\title{
Registro poligráfico de proxémica corporal y temática
}

Jesús Becerra Villegas ${ }^{1}$

\section{Propósito}

\begin{abstract}
C
ON EL FIN DE DESARROLLAR un estudio sobre los efectos de los cambios en las disposiciones proxémicas en un sujeto, se realizó un ejercicio apoyado en el uso de un polígrafo el cual registró la actividad corporal (en orden descendiente en el papel) con dos sensores de microvolts en la zona occipital para monitorear la actividad cerebral de los dos hemisferios (electroencefalograma o EEG), dos más en la frente, sobre cada ceja, para registrar el promedio del movimiento muscular supraocular (electromiograma o EMG) y el último un milisensor en la muñeca izquierda, que midió la frecuencia cardiaca reflejada en las pulsaciones de la arteria radial (electrocardiograma o ECG).

Mediante este estudio se pretendió determinar si había correspondencia entre las distancias en que son recibidos los estímulos de presencia corporal y los de temas de conversación, por una parte, y los ritmos de trabajo cerebral, muscular facial y cardiaco. La hipótesis general con que se trabajó consideraba que habría alguna respuesta cognoscitiva y emocional reflejada en el polígrafo.
\end{abstract}

\section{Antecedentes / Importancia}

La proxémica es una rama de la semiología que tiene por objeto de estudio las distancias y las disposiciones corporales de los interlocutores, en tanto que todo ello supone un mensaje por sí mismo, en el mismo sentido de la conversación o

1. Universidad Autónoma de Baja California. 
en un sentido opuesto. Así pues, un estudio sobre cercanías y lejanías entre dos sujetos es un asunto de proxémica. Sin embargo, un estudio sobre la "distancia" emocional del discurso es más bien inédito para el dominio de la proxémica tradicional.

En el oficio periodístico se parte de que las notas son jerarquizables en función del "radio de efecto" de la misma: son más importantes aquellas que afectan más inmediatamente al lector-objetivo, que las de trascendencia mayor. En ese sentido, un temblor de ocho grados Richter al otro lado del planeta es de menor jerarquía noticiosa que uno local de apenas cuatro.

El estudio efectuado buscó medir la "intensidad" diferencial de los mensajes referida en la respuesta del sujeto de estudio, a partir de su proximidad emocional, a la vez que se variaban también las distancias físicas entre el sujeto estudiado y los sujetos observadores. Aun como mero intento, esto es por sí mismo relevante, puesto que implica la posibilidad de ensanchar las fronteras de los estudios de proxémica, tradicionalmente "topográfica", para ser ahora "temática".

\section{Metodología}

El estudio consistió en una observación de aproximadamente 30 minutos en el área de laboratorios y talleres de la Facultad de Ciencias Humanas de la Universidad Autónoma de Baja California. Los sujetos participantes fueron tres: una egresada de la carrera de ciencias de la comunicación, como sujeto observado, y dos profesores varones observadores, uno de la misma carrera y el otro de la carrera de psicología. El espacio de trabajo fue el área de registros del laboratorio de psicofisiología, que consta de dos cubículos contiguos: uno para el sujeto observado y otro para los observadores y equipo; anexa se encuentra una sala de usos múltiples que en el momento del estudio se utilizaba como aula, de manera que el ruido propio de la clase podía ser percibido por el sujeto estudiado.

Se utilizó como equipo de registro un polígrafo con cuatro lecturas, conforme a lo que se indicó en la primera sección; encéfalo, mio y cardiográfica; dos cámaras Súper VHS, que registraron en lo visual tanto al sujeto estudiado como el polígrafo en su funcionamiento, y en lo auditivo grabaron el mismo sonido ambiental, lo que permitió sincronizar las cintas en una edición posterior. También se colocó una lámpara "placebo" a un lado del sujeto estudiado, la cual se suponía que iba a encenderse repentinamente, para proporcionar el estímulo cuya respuesta era la que se "pretendía" registrar.

El sujeto estudiado es una joven egresada el semestre anterior, familiarizada con el equipo de video y con los registros poligráficos. La relación personal entre 
ella y el conductor del estudio es de confianza desde algunos semestres atrás, cuando él fungió como su tutor académico y luego como su profesor. Por estas características ella fue seleccionada como sujeto de estudio. Se le planteó que se haría una prueba de respuestas a estímulos visuales consistentes en el encendido de una lámpara mientras ella permanecía con los ojos cerrados. Se decidió dar esta información para evitar partir de expectativas que modificaran la respuesta atenuándola o intensificándola. En realidad, los estímulos que interesaba atender eran, por una parte, los de la proximidad, consistentes en acercamientos hacia ella "para acomodar" los sensores electroencefalográficos y, por la otra parte, los estímulos de contenido de mensaje o temáticos, prioritariamente.

El estudio comenzó con algunas pruebas de registro en las que se midieron algunos movimientos a velocidad baja, que luego fue incrementada a $30 \mathrm{~mm} / \mathrm{seg}$., para observar con mayor claridad las respuestas en el poligrafo. En esa nueva velocidad se continuaron algunas pruebas y se permitió que el sujeto de estudio se relajara, lo cual fue registrado principalmente en el EEG, en el que se observó el trabajo cerebral que llegó a frecuencia alfa. Una vez con las condiciones apropiadas, los profesores procedieron a sostener un diálogo preconcebido, que se hizo parecer casual y que fue suficientemente audible e intercalado con acercamientos al sujeto de estudio. El diálogo se refirió a lo siguiente:

1. Se preguntó si hubo un temblor en ese momento, que se habría detectado con certeza por el hecho de encontrarse el área de estudio en un segundo piso y por haber estado en funcionamiento el polígrafo, que supuestamente lo habria detectado. La respuesta del interlocutor fue negativa, pero fue el pretexto para hablar de un supuesto temblor muy fuerte en un país lejano, en el que se presentaron víctimas.

Expectativa: El pequeño temblor local generaría mayor ansiedad que la noticia de una catástrofe del otro lado del mundo.

2. Se comentó que la institución de la cual es recién egresada la persona en estudio recientemente había incrementado los costos de titulación.

Expectativa: Habría alguna respuesta física del sujeto de estudio ante la información de que tendría que desembolsar ahora una cantidad mayor para obtener su título profesional.

3. El profesor a cargo del polígrafo le solicitó al conductor del estudio, con quien tiene más familiaridad la persona en observación, que se acercara a ella para cerciorarse de una supuesta falla en el polígrafo por efecto de interferencia.

Expectativa: El acercamiento corporal debería traducirse en alguna reacción cerebral, facial o cardiaca.

4. El profesor a cargo del polígrafo le comentó al conductor del estudio sobre la existencia de una vacante en una institución escolar, por lo que debería hacer llegar éste su curriculum en caso de interesarse por el posible empleo. 
Expectativa: Debido a que la persona en estudio debe un ejemplar de curriculum que el conductor del estudio le facilitó, se esperaba que la referencia al documento adeudado produjera una cierta ansiedad detectable en los sensores.

\section{Análisis de resultados}

Durante la ejecución de la prueba, se detectaron fluctuaciones bruscas del EEG explicables mayormente por una mera interferencia física que se provocaba al acercarse un segundo sujeto a la persona en estudio. Así, la pretendida interferencia que constituía un pretexto para acercarse, terminó por ocurrir en los hechos.

Lo anterior y la declaración de la persona en estudio respecto a no sentir ninguna cohibición ante la proximidad física, hicieron suponer inicialmente que la prueba había fracasado al menos en la parte de la proxémica corporal. Sin embargo, un estudio posterior en el par de videos editados en sincronía mostró que efectivamente había parte de la respuesta en los sensores que se explicaba por la interferencia física, mas una vez traspasado el rango de ésta, la respuesta era producida por el sujeto, tanto a nivel de EEG como de EMG.

Así pues, sí hubo respuestas a la proxémica corporal, detectables a través de estos electrosensores, aun cuando el nivel de confianza y la relajación de la persona estudiada eran altos, como lo indicó el ECG al mostrar una tendencia a largo plazo de disminución del ritmo cardiaco.

En lo que corresponde a la proxémica temática, como se apuntó, se sostuvo un diálogo a partir de un guión general. Los resultados se presentan a continuación, para cada una de las cuatro partes referidas en la sección anterior:

1. El temblor: Se comenzó hablando de un pequeño temblor local, lo que produjo una pérdida inmediata de ondas alfa, propias de los estados de relajación; luego se habló de un terremoto en Afganistán, cuando ya el sujeto se encontraba nuevamente en estado alfa, del que no salió ante la noticia de la catástrofe lejana. La respuesta músculo facial parece ser menor también a la segunda parte del diálogo, si bien este registro no resulta muy fiable durante este diálogo en particular debido a que la persona en estudio mostraba cierto trabajo facial inmediatamente antes de iniciar cl mismo.

2. El alza en las cuotas: A nivel de EEG y de EMG no se observan suficientes cambios en los registros (los cambios en ECG son visibles a largo plazo). La persona en estudio manifestó no haberse preocupado por la noticia, debido a que no sería ella quien tuviese que pagar su titulación. Sin embargo, se observó luego en el video editado un trago de saliva en el momento justo en que se mencionaba el alza, dentro del contexto de un diálogo más amplio. 
3. La interferencia física: Como ya se comentó, se esperaba una cierta respuesta a un acercamiento forzado para descartar una supuesta interferencia que sí existió en los hechos; sin embargo, el problema sólo se dio en una zona entre el sillón donde se encontraba la persona estudiada y el polígrafo. La proximidad mayor, incluso con contacto físico, arrojó datos de respuesta de la persona y no de la interferencia.

4. El documento adeudado: El comentario comenzó con generalidades que provocaron una mera respuesta de recepción, en tanto que irrumpió la tranquilidad de la espera, ya muy marcadamente en estado alfa. La referencia al curriculum causó por sí mismo poco impacto, pero sí es notorio su mención en el registro. Poco después se produjo una cierta actividad facial durante varios segundos; sin embargo, en tanto no se puede adivinar el curso concreto de los pensamientos de la persona, sólo cabe anotar como probabilidad que la respuesta haya estado asociada a la mención ya referida.

\section{Conclusiones y recomendaciones}

La principal conclusión que se deriva de esta experiencia de trabajo es que sí existe, al menos para el caso estudiado, algo como una proxémica conceptual que complementa del lado del receptor y de su psicología la proxémica espacio corporal sea del emisor o del receptor.

Lo interesante en esto es que se trata de un estudio empírico que apoya un planteamiento derivable directamente de la semiótica y de las teorías de los actos comunicativos. Habría que considerar, quizá, las variaciones proxémicas en los hechos cotidianos como manifestaciones en respuesta a las actitudes de proximidad temática. Es decir, si bien la proxémica como tal es entendible como mensaje "de ida", puede resultar más válido comenzar a verla como mensaje "de venida". En los estudios etnográficos tal diferencia puede ser potencialmente rica para orientar el sentido de lo observado.

Por lo demás, pueden ofrecerse las siguientes consideraciones y algunas líneas de trabajo y recomendaciones:

Los estudios que se hacen regularmente en el Laboratorio de Psicofisiología de la Facultad de Ciencias Humanas de la Universidad Autónoma de Baja California, no son apoyados por cámaras de video ni son guiados por hipótesis que rebasen el dominio de las neurociencias, por lo cual el presente trabajo constituyó una experiencia inédita en este espacio académico. Incluso, como se comentó, la edición sincrónica de las imágenes del sujeto observado y el registro poligráfico permitió rescatar lo que se creyó fallido. Esta experiencia podría ampliarse a otras instituciones. 
- Una lectura más cuidada en cuanto a interferencias físicas y diversificada en cantidad de sensores puede arrojar mayores datos. Por ejemplo, en EMG puede intentarse una detección de paso de saliva y de movimientos de labios y de pies.

- Pueden hacerse registros de respuesta proxémica en estado de sueño y en estado de vigilia.

- Puede diversificarse la cantidad de observaciones en distintos sujetos, variando sexo, edad y familiaridad con los estudios y con los observadores.

- Puede variarse el espacio de trabajo a fin de que los sujetos ganen en espontaneidad al no saberse observados, tal como to permiten los laboratorios equipados con cámaras de Gessell.

- La duración de las observaciones parece ser adecuada en un tiempo de treinta minutos para el estado de vigilia, puesto que después de ese lapso, los sujetos estudiados tienden a relajar sus respuestas a los estímulos.

- Es recomendable mantener a los sujetos en estudio ajenos a los verdaderos propósitos de las observaciones, a fin de que las expectativas que asumen que se tienen respecto a ellos no contaminen sus respuestas.

En lo general, los estudios relacionados con el dominio de los procesos simbólicos parecen haber sido escasamente abordados mediante procesos experimentales o cuasi experimentales.

Sin pretender que el ejercicio referido constituya un caso ejemplar por carecer de algunos amarres fundamentales en la metodología cuantitativa, sí se muestra la posibilidad de abrir líneas de pensamiento y de acción en la construcción de una semiótica más cercana al espacio de lo ex-tensional, que parece haber sido confinado a lo extrasemiótico. 